Classification

Physics Abstracts

$47.55-91.60-07.05$

\title{
2D Connectivity of Soultz Granite Primary Minerals
}

\author{
Paul Sardini $\left({ }^{1}\right)$, Éric Moreau $\left({ }^{2}\right)$, Alain Meunier $\left({ }^{1}\right)$ and Gérard Touchard $\left({ }^{2}\right)$ \\ $\left({ }^{1}\right)$ Laboratoire Hydrogéologie, Argiles, Sols et Altérations, URA 721 du CNRS, \\ 40 avenue du Recteur Pineau, 86022 Poitiers Cedex, France \\ $\left({ }^{2}\right)$ Laboratoire de Physique et Mécanique des Fluides, LEA, URA 191 du CNRS, \\ 40 avenue du Recteur Pineau, 86022 Poitiers Cedex, France
}

\begin{abstract}
Résumé. - Dans le granite sain de Soultz-sous-Forêts, l'application de méthodes de traitement et d'analyse d'images 2D permet de caractériser, à l'échelle macroscopique, certains chemins d'écoulement des fluides. La saisie et le traitement adaptés des images permettent tout d'abord d'obtenir une représentation spatiale bidimensionnelle des 4 minéraux primaires du granite. Létude de la connexité des amas de cristaux appartenant à une espèce minérale donnée montre que le plagioclase et le quartz forment des amas de cristaux de grande taille, probablement connectés en 3D. Lextraction de joints de grains inter-espèces fournit une représentation réelle $2 \mathrm{D}$ d'un réseau d'écoulement potentiel des fluides. Une étude par microscopie électronique complète ces mesures.
\end{abstract}

\begin{abstract}
In the fresh facies of the Soultz-sous-Forêts granite, fluid flow paths need to be characterized. Application of 2D image treatment and analysis is used here to characterize some flow paths at macroscopic scale. First, using a suitable image acquisition method, a spatial bidimensional representation of the four granite primary minerals is obtained. Connectivity studies of crystal clusters of mineral species shows that plagioclase and quartz form large size clusters, probably $3 \mathrm{D}$ connected. Inter-species grain boundaries extraction give a $2 \mathrm{D}$ representation of a potential fluid flow path. A quantitative S.E.M. study is added to these measurements.
\end{abstract}

\section{Introduction}

The Soultz-sous-Forets granite (Alsace, France) is the site of an intense thermal anomaly. Consequently, it is presently investigated as a potential Hot-Dry-Rock (HDR) geothermal site [1,2]. The application of image acquisition, treatment and analysis methods to characterize fluid path networks in the unaltered granite facies are presented here. Traditional granite flow path studies use microscopic images to locate and quantify microporosity [3]. The Soultz granite, which is a medium grained granite (average grain size: $5 \mathrm{~mm} \mathrm{[4])} \mathrm{is} \mathrm{studied} \mathrm{here} \mathrm{at} \mathrm{the} \mathrm{scale} \mathrm{of} \mathrm{pieces} \mathrm{of}$ drill core. The microscopic method [5] cannot enhance the contrast between mineral species on a large area to be representative. Macroscopic image acquisition allows us to obtain images representing the spatial distribution of the four primary minerals of the granite (plagioclase, quartz, 


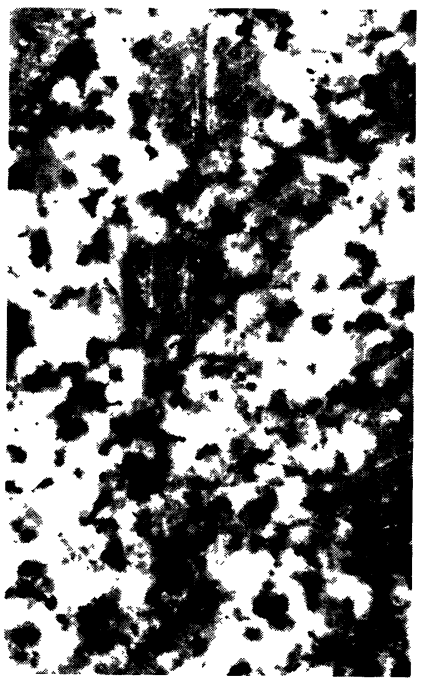

a)

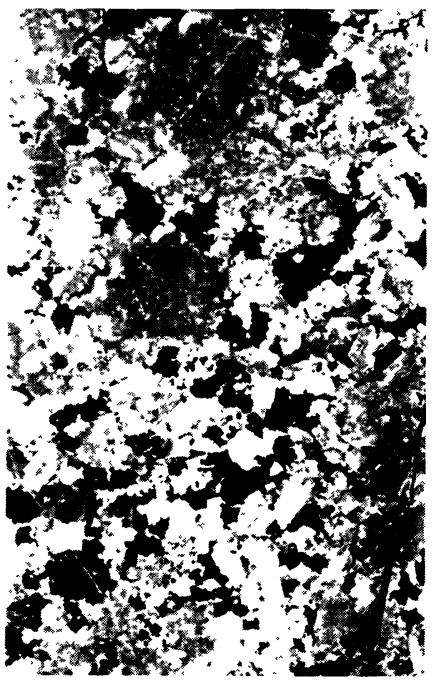

b)

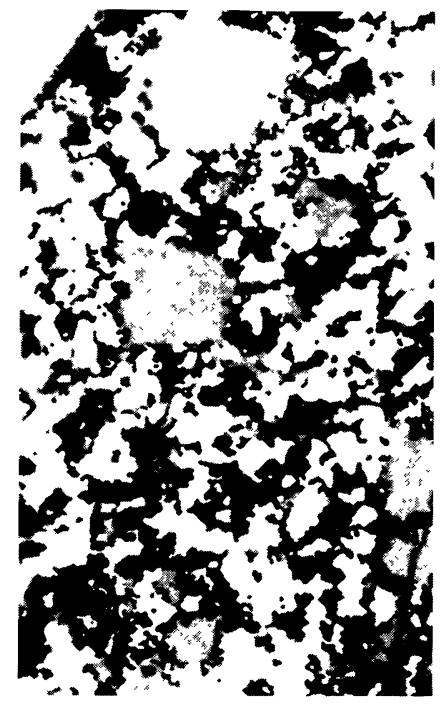

c)

Fig. 1. - Different steps of image treatment. a) Initial b/w 8-bit image, b) 24-bit colour image, c) fourcolour final image (false colour, image size: $498 \times 812$ pixels, $62 \times 101 \mathrm{~mm}$ ).

orthoclase and dark minerals). Determination of the connectivity of the four major constituents in the granite is important in order to quantify fluid flow paths in granite:

1) the connectivity of crystal clusters of a unique species gives information about the existence of potential flow paths across the core sample, through this mineral species [6];

2) the connectivity between crystals which are not of the same mineral species (called inter-species connectivity) provides information on percolation networks associated with grain boundaries.

\section{Image Acquisition and Treatment}

Several steps are used to obtain images representing the four primary minerals:

1) The initial half-core pieces are scanned with a colour Canon CLC 300 scanner driven by a Silicon Graphics workstation (8 bits per pixel, $200 \mathrm{dpi}$ ) using grey level mode. An example of a scanned core piece is illustrated in Figure 1a. The threshold has been performed on this image to extract the dark minerals, which contrast greatly with the surrounding matrix.

2) After a chemical etching of the surface by hydrofluoric acid vapors at $40^{\circ} \mathrm{C}$ for three minutes, the sample is stained with $\mathrm{Na}$-cobaltinitrite. As a result, three mineral phases can be distinguished macroscopically: plagioclase (white), orthoclase (yellow), and quartz (grey). Dark minerals are indifferentially stained in one of these three colour. The stained sample is then scanned ( 24 bit per pixel, 200 dpi) using RGB mode (Fig. 1b). At this point, some regions of quartz are confused with plagioclase, and inversely, some regions of plagioclase are confused with quartz. The three colors are thresholded simultaneously to obtain a three-colour image (Fig. 2).

3) The two scanned images are superimposed, providing an image on which the four minerals species can be discriminated. 


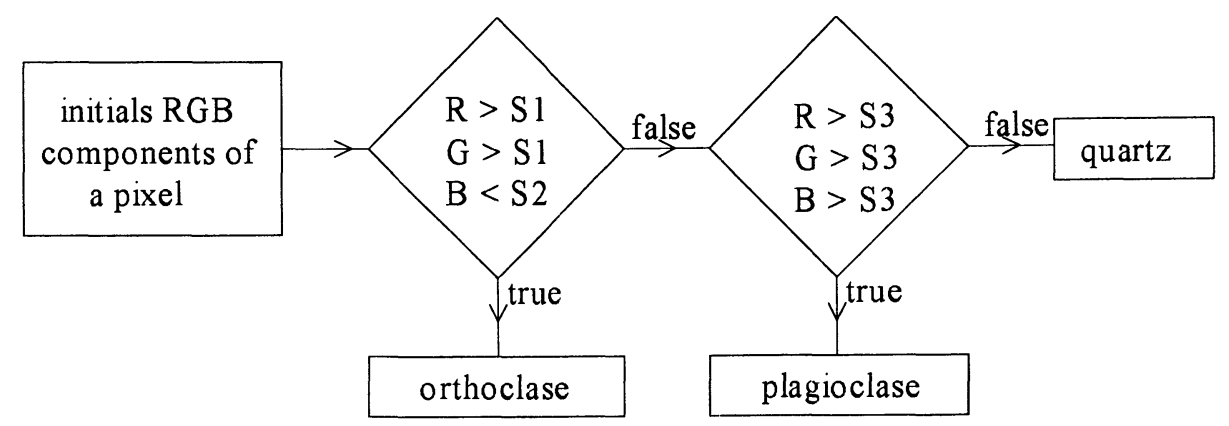

Fig. 2. - Threshold process of the 24-bit in three-colour images.

4) Finally, an adaptative filtering is applied to remove small clusters of pixels: an 8-neighbourhood mask is applied, and the colour which is most representative of the whole mask is assigned to the central pixel. A final correction of the image is done manually by removing dark inclusions in orthoclase megacrysts and milky fractures in quartz crystals.

In spite of problems during the threshold of 24-bit images, it appears that the final images (Fig. 1c) acceptably represent the spatial distribution of the four granite primary minerals. The connectivity of crystal clusters of each mineral species is then analysed.

\section{Connectivity of Crystal Clusters of the Same Mineral Species}

Quantification of the connectivity of granite primary mineral clusters provides information on the existence of a percolation network, for a given mineral species.

Connectivity is a concept from percolation theory which describes the properties of groups of objects arranged in space. These objects intersect to form clusters, and at a certain density of objects, a theoretically infinitely large cluster is formed [7]. To quantify the connectivity of crystal clusters of a given mineral, we define the connectivity index $I_{\mathrm{r}}$ by the following relation:

$$
I_{\mathrm{r}}=1-N_{\text {clusters }} / N_{\text {crystals }}
$$

where $N_{\text {clusters }}$ corresponds to the number of crystal clusters, and $N_{\text {crystals }}$ represents the total number of crystals belonging to these clusters. It is considered here that $N_{\text {crystals }}$ is represented by the number of ultimate eroded sets [8] of the clusters. The ultimate eroded are dilated one time to coalesce the ultimate eroded which are too close. $I_{\mathrm{r}}$ equals 0 if $N_{\text {crystals }}$ equals $N_{\text {clusters }}$ (all crystals are disconnected), and $I_{\mathrm{r}}$ is near unity if $N_{\text {crystals }} \gg N_{\text {clusters }}$ (all crystals are connected).

The validity of this connectivity index has been checked by a simple simulation. Full disks were randomly projected on a square image $(500 \times 500$ pixels, radius of the disks 10 pixels, Fig. 3a). Figure $3 \mathrm{~b}$ presents the evolution of $I_{\mathrm{r}}$ and the probability of percolation $P$ versus area fraction $p$ (total area occupied by the disks divided by total analysis area). In Figure $3 \mathrm{~b}$, each point represents an average calculated for 100 simulated images. For values of area fraction lower than the percolation threshold, a linear variation of $I_{\mathrm{r}}$ versus $p$ is observed. For this system, the proposed index is adapted to the connectivity study of disk clusters, especially under the percolation threshold.

The connectivity index was calculated on four images corresponding to four half core granite samples. Figure $3 \mathrm{c}$ presents $I_{\mathrm{r}}$ values for each mineral according to its corresponding area fraction. For a given sample (except for K7-3), the following connectivity sequence are observed: $I_{\mathrm{r}}($ plagioclase $)>I_{\mathrm{r}}($ quartz $)>I_{\mathrm{r}}($ dark minerals $)>I_{\mathrm{r}}($ orthoclase $)$. This sequence respects 


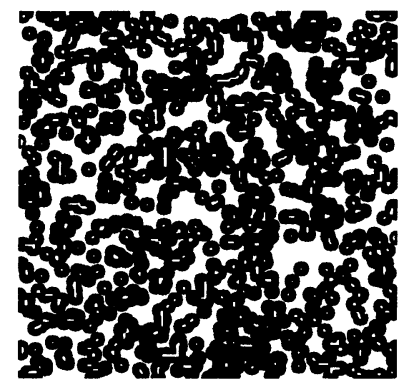

a)

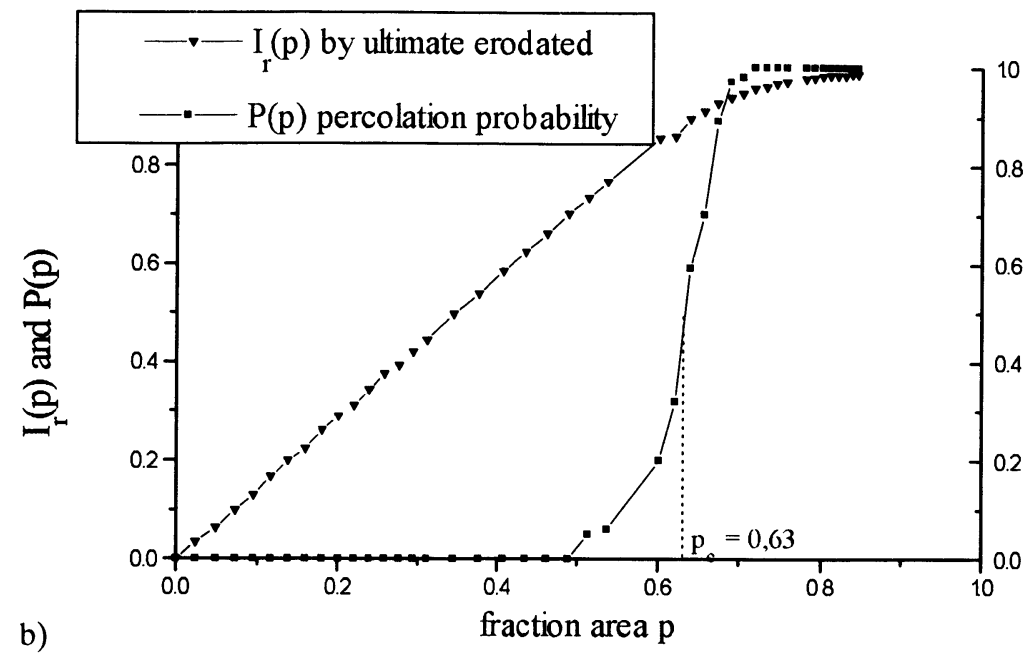

b)

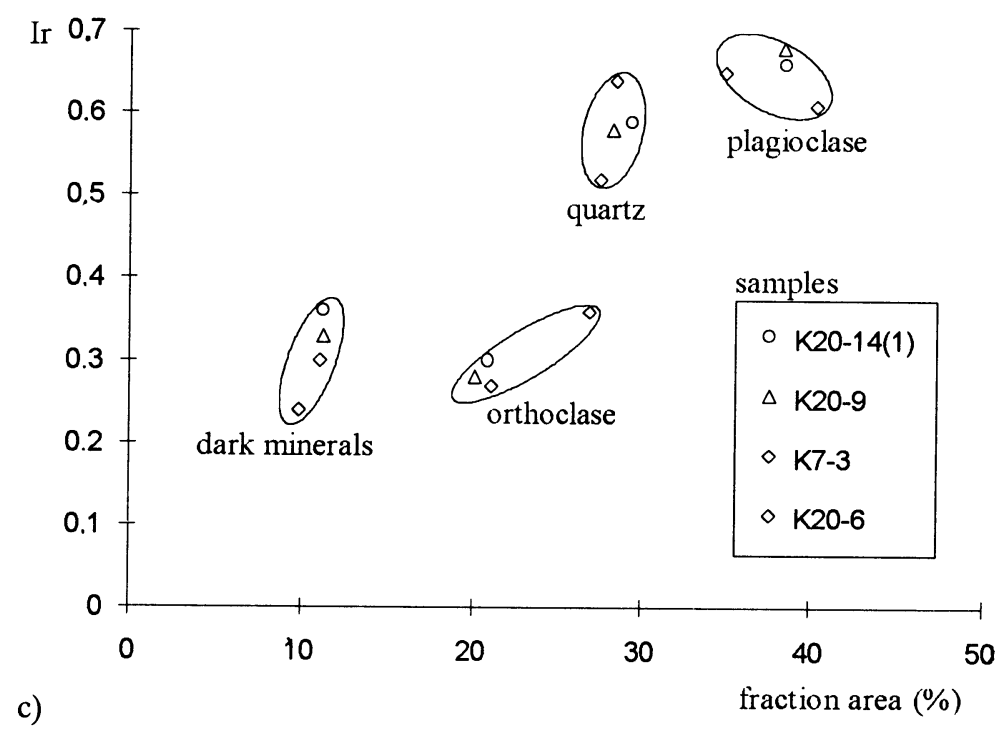

Fig. 3. - a) Simulation using full disks, randomly projected on a $500 \times 500$ image, and their ultimate eroded sets, and b) calculation of connectivity index $I_{\mathrm{r}}$ and percolation probability $P$ versus fraction area. In c), the connectivity index versus fraction area for each granite mineral species is shown.

the increase of the area fraction occupied by minerals, except for the orthoclase. Orthoclase represents about $20 \%$ of the total area, but its connectivity is lower than that of dark minerals which represent only $10 \%$ of the total area. This can be explained by the fact that a large part of the orthoclase area is represented by isolated megacrysts, each of which determines a single ultimate eroded set.

As a result, two mineral groups can be distinguished by their mean connectivity index. 1) Plagioclase and quartz, with a connectivity index higher than 0.5 . Plagioclase and quartz were used for microscopic study [9], because of their high probability of $3 \mathrm{D}$ connectivity. These two mineral species can define two percolation networks in the unaltered granite. 
2) Dark minerals and orthoclase with a connectivity index lower than 0.4 . Since dark minerals and orthoclase are poorly connected, we assume that they are under the critical percolation threshold. These two phases cannot define percolation networks across the granite, but may be efficient for fluid flow.

\section{Inter-Species Connectivity}

Inter-species connectivity is defined by the contact area between crystals of different minerals species. These contact area are called inter-species boundaries. If the boundary is open, it is called an inter-species grain boundary microcrack (ISGBM). Four-colour images are used here to obtain a $2 \mathrm{D}$ representation of percolation networks associated with inter-species boundaries. To determined the probability of opening of these boundaries, a quantitative microscopic study is also done.

Total inter-species boundaries (Fig. 4a) is obtained by four-colour images (Fig. 1c), and corresponds to all the boundaries between the four primary minerals. Partial inter-species boundaries (example of plagioclase-quartz network Fig. 4b) corresponds to boundaries located between two given mineral species. These networks are skeletonized on an octogonal graph [8] to thin the boundaries to a unitary thickness.

The main parameter quantified is surface area per unit volume $\left(S_{\mathrm{v}}\right)$ for each type of boundaries. $S_{\mathrm{v}}$ is linked to $L_{\mathrm{a}}$ (length per unit test area) by the relation [10]:

$$
S_{\mathrm{v}}=(4 / \pi) L_{\mathrm{a}} .
$$

$L_{\mathrm{a}}$ is twice the skeleton length, which is determined by image analysis. Mean total $S_{\mathrm{v}}$ is thus equal to $1.73 \mathrm{~mm}^{-1}$. The longer partial network is plagioclase-quartz, representing about $40 \%$ of the total $S_{\mathrm{v}}$. The quartz-dark mineral network represents $20 \%$ of the total $S_{\mathrm{v}}$. However, these measurements do not characterize the actual fluid flow paths, because they might not correspond to ISGBM. Quantification by S.E.M. microscopy (backscattered electron mode) was also done. This is necessary 1) to quantify the probability of opening of boundaries according to the minerals adjoining it, and 2) to determine the opening of observed ISGBM. A linear scan across thin sections was used to determine these parameters. The number of intersections of the scanning line with inter-species boundaries per unit length $P_{1}$ is determined. High magnification $(\times 5000)$ is used to check microcracks opening, and to evaluate it. Surface area per unit volume is given by Underwood [10]:

$$
S_{\mathrm{v}}=2 P_{1} .
$$

The mean value of $S_{\mathrm{v}}$ is equal to $2.41 \mathrm{~mm}^{-1}$. The plagioclase-quartz interface represents about $30 \%$ of the total surface area per unit volume. The observed difference with the calculation relative to the four-colour images $\left(1.73 \mathrm{~mm}^{-1}\right)$ is explained by the resolution used. On macroscopic images, the smallest grain size taken into account is $400 \mu \mathrm{m}^{2}$, whereas it is $50 \mu \mathrm{m}^{2}$ using SEM quantification. The probability of opening varies considerably according to the type of minerals adjoining the boundaries. It varies between $95 \%$ (quartz-dark minerals) and $11 \%$ (orthoclaseplagioclase). Plagioclase-quartz interfaces are $60 \%$ open. Mean estimated ISGBM opening varies between $2 \mu \mathrm{m}$ (quartz-dark minerals) and $0.4 \mu \mathrm{m}$ (plagioclase-dark minerals).

\section{Conclusions}

Determination of connectivity between the primary minerals in the Soultz granite by macroscopic image analysis techniques allows a new prospective. 


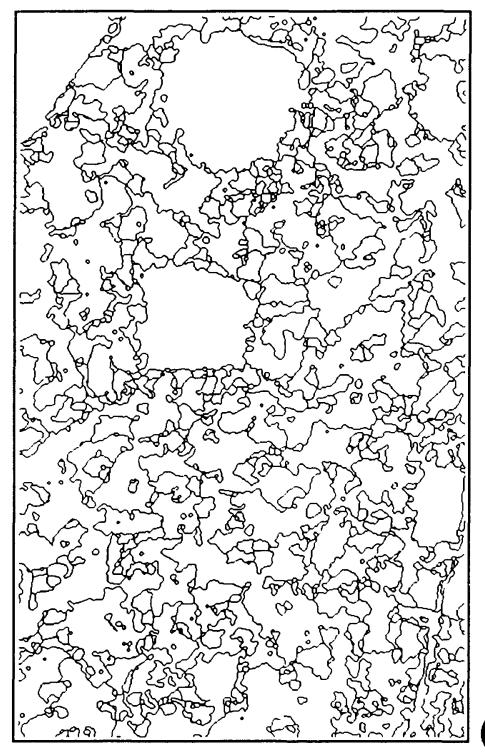

(a)

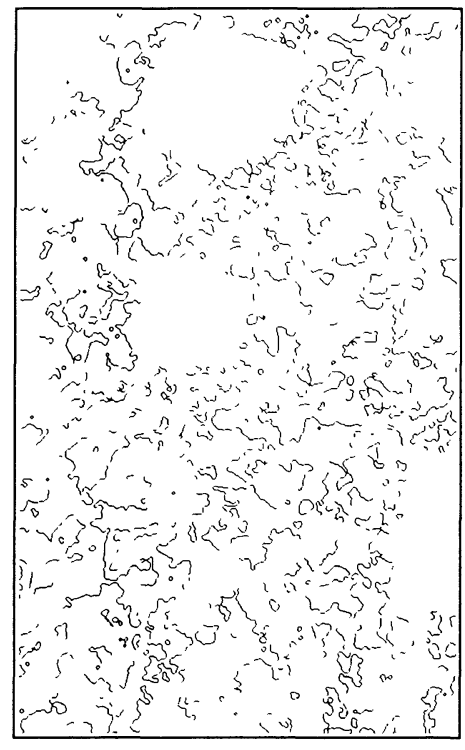

(b)

Fig. 4. - In a), Total inter-species boundary network, and in b), partial inter-species boundary network between plagioclase and quartz.

The study of connectivity of mineral clusters of the same species tells about the existence of fluid flow paths linked to one given mineral species [6]. However, plagioclase and quartz microporosity need to be microscopically studied [9]. The connectivity index used also need to be tested for 3D cases, for example on 3D simulated media [11].

Inter-species boundaries determination enables to simulate real and representative network of inter-species grain boundary microcracks. The total network of inter-species boundaries allows bidimensional visualization of a potential flow network in the granite. Taking inter-species boundaries opening probabilities into account, simulation of inter-species grain boundary microcracks network is now possible. The mean openings determined by SEM are necessary for numerical calculations of permeability. Intra-species boundaries could also be taken into account by the application of a particle separation algorithm [8]. These types of real percolation networks can replace regular networks used in traditional simulations.

\section{References}

[1] Elsass P., Aquilina L., Beauce A., Benderitter Y., Fabriol H., Genter A. and Pauwels H., Deep structures of the Soultz-sous-Forêts HDR site (Alsace, France), Proc. World Geothermal Congress, Florence, Italy 4 (1995) 2643-2647.

[2] Baria R., Gérard A., Baumgärtner J. and Garnish J., Progress at the European HDR site at Soultz, France, 3rd International HDR Forum, Santa Fe, NM, USA (1996) 73-74.

[3] Wang H.F., Bonner B.P., Carlson S.R., Kowallis B.J. and Heard H.C., Thermal stress cracking in granite, J. Geophys. Res. 94 (1989) 1745-1758.

[4] Genter A., Géothermie Roches Chaudes Sèches. Le granite de Soultz-sous-Forêts (Bas-Rhin, France), Thèse de l'Université d'Orléans (1989). 
[5] Tricart J.P., Caractérisation des roches réservoirs par analyse d'images pétrographiques, Bull. C. Rech. Explor-Prod. Elf Aquitaine 8 (1994) 207-217.

[6] Ledésert B., Joffre J., Amblès A., Sardini P., Genter A. and Meunier A., Organic matter in the Soultz HDR granitic thermal exchanger (France): natural tracer of fluid circulations between the basement and its sedimentary cover, J. Volc. Geoth. Res. (1996) 1-19.

[7] Stauffer D., Introduction to Percolation Theory (Taylor and Francis, London, 1985).

[8] Coster M. and Chermant J.-L., Précis d'analyse d'images (Les Presses du CNRS, 1989).

[9] Sardini P., Ledésert B. and Touchard G., Quantification of microscopic porous networks by image analysis and measurements of permeability in the Soultz-sous-Forêts granite (Alsace, France), in Fluid flow and transport in rocks, Conf. Vol. of Kongsberg Seminar, Norway (Chapman and Hall, 1996).

[10] Underwood E.E., Quantitative Stereology (Addison Wesley, 1970).

[11] Adler P.M., Jacquin C.G. and Thovert J.-F., The formation factor of reconstructed porous media, Water Resour: Res. 28 (1992) 1571-1576. 